Consultant of: AbbVie, Amgen, Astellas, AstraZeneca, BMS, Boehringer Ingelheim, Celgene, Cyxone, Daiichi, Eisai, Eli-Lilly, Galapagos, Gilead Sciences, Inc., Glaxo-Smith-Kline, Janssen, Merck, Novartis, Pfizer, Regeneron, Roche, Sanofi, Takeda, UCB Pharma; Director of Imaging Rheumatology BV, Anna Wiksten Shareholder of: Novartis, Employee of: Novartis, Brian Porter Shareholder of: Novartis, Employee of: Novartis, Hanno Richards Shareholder of: Novartis, Employee of: Novartis, Sibylle Haemmerle Shareholder of: Novartis, Employee of: Novartis, Atul Deodhar Grant/research support from: AbbVie, Eli Lilly, GSK, Novartis, Pfizer, UCB, Consultant of: AbbVie, Amgen, Boehringer Ingelheim, Bristol Myer Squibb (BMS), Eli Lilly, GSK, Janssen, Novartis, Pfizer, UCB, Speakers bureau: AbbVie, Amgen, Boehringer Ingelheim, Bristol Myer Squibb (BMS), Eli Lilly, GSK, Janssen, Novartis, Pfizer, UCB DOI: 10.1136/annrheumdis-2020-eular.598

\section{OP0107 ETANERCEPT WITHDRAWAL AND RE-TREATMENT IN PATIENTS WITH INACTIVE NON-RADIOGRAPHIC AXIAL SPONDYLOARTHRITIS AT 24 WEEKS: RESULTS OF RE-EMBARK, AN OPEN-LABEL, PHASE IV TRIAL}

F. Van den Bosch ${ }^{1}$, J. C. C. Wei ${ }^{2}$, P. $\mathrm{Nash}^{3}$, F. J. Blanco ${ }^{4}$, D. Graham ${ }^{5}$, C. Zang ${ }^{5}$, E. Arthur ${ }^{6}$, C. Borlenghi ${ }^{7}$, B. Vlahos ${ }^{5}$, A. Deodhar ${ }^{8} .{ }^{1}$ Ghent University Hospital, Gent, Belgium; ${ }^{2}$ Chung Shan Medical University Hospital, Taichung, Taiwan, Republic of China; ${ }^{3}$ Griffith University, Brisbane, Australia; ${ }^{4}$ INIBIC-Hospital Universitario A Coruña, La Coruña, Spain; ${ }^{5}$ Pfizer, Collegeville, United States of America; ${ }^{6}$ Pfizer, New York, United States of America; ${ }^{7}$ Pfizer, Buenos Aires, Argentina; ${ }^{8}$ Oregon Health \& Science University, Portland, United States of America

Background: In the RE-EMBARK trial (NCT02509026), etanercept (ETN)treated patients with non-radiographic axial spondyloarthritis (nr-axSpA) who achieved inactive disease (defined as Ankylosing Spondylitis Disease Activity Score with C-reactive protein $[$ ASDAS CRP] $<1.3)$ in Period $1(\mathrm{P} 1)^{1}$ discontinued ETN for $\leq 40$ weeks.

Objectives: To assess the proportion of patients with inactive disease after P1 who experienced disease flare (ASDAS with erythrocyte sedimentation rate [ASDAS ESR] $\geq 2.1$ ) within 40 weeks of ETN withdrawal and to estimate time to flare following ETN withdrawal.

Methods: RE-EMBARK was a multicenter, open-label, Phase IV trial of ETN in patients with active nr-axSpA (meeting Assessment in SpondyloArthritis international Society criteria and with ASDAS CRP $\geq 2.1$ ) and an inadequate response to $\geq 2$ nonsteroidal anti-inflammatory drugs (NSAIDs) while taking a stable dose of 1 NSAID for $\geq 2$ weeks before the first ETN dose. All patients received ETN (50 mg/ week) plus NSAID for the first 24 weeks (P1). At week 24, patients with inactive disease discontinued ETN for $\leq 40$ weeks (Period 2 [P2]). Those who experienced flare during P2 were re-treated with ETN for 12 weeks in Period 3 (P3). Kaplan-Meier (KM) analysis and Cox proportional hazard models were used to 1) estimate the probability of experiencing flare within a given time period, and 2) compare data between RE-EMBARK and the EMBARK trial (NCT01258738) of patients with nr-axSpA who met RE-EMBARK P2 entry criteria (achieved inactive disease after 24 weeks of ETN treatment) and continued treatment for a further $\leq 40$ weeks.

Results: Of the 209 patients in P1 (mean age, 33 years; women, 46\%; white, $89 \%), 119(57 \%)$ entered P2. The proportion of patients experiencing $\geq 1$ flare increased from 22\% (25/112) at P2 week 4 to $67 \%(77 / 115)$ at P2 week 40. Overall, $75 \%$ (86/115) of patients in P2 experienced flare and 50\% experienced flare within 16 weeks (95\% Cl: $13-24$ weeks, KM analysis). Conversely, data from the comparator EMBARK trial suggested that $<25 \%$ of patients receiving continuous ETN treatment over 40 weeks experienced flare. Cox proportional hazard model analysis showed an $85 \%$ relative risk reduction of experiencing flare during P2 in patients with inactive disease who continued ETN treatment vs those who discontinued. By P3 end 62\% (54/87) of patients re-treated with ETN re-achieved inactive disease; $50 \%$ of patients who re-achieved inactive disease in P3 did so within 5 weeks (95\% Cl: 4-8 weeks, KM analysis). The observed trend of clinical improvement (P1), worsening (P2), and improvement (P3) was reflected in other clinical measures (Figure) plus measures of joint damage (Spondyloarthritis Research Consortium of Canada Sacroiliac Joint magnetic resonance imaging score) and quality of life (EQ-5D visual analog scale score); mean (standard deviation) score changes from each study period baseline-end were -6.1 (11.7) [P1], +1.5 (4.4) [P2], -2.0 (8.8) [P3] and +27.7 (26.7) [P1], -26.4 (30.5) [P2], +32.1 (26.3) [P3], respectively. There were no unexpected safety signals.

Conclusion: For patients with nr-axSpA who achieved inactive disease with ETN and then discontinued treatment, a quarter maintained treatment-free inactive disease for 40 weeks and $50 \%$ maintained an ASDAS ESR score of $<2.1$ for $\geq 16$ weeks. Re-starting ETN allowed $62 \%$ of patients who flared to re-achieve inactive disease within 12 weeks.

\section{References:}

[1] Van den Bosch F, et al. Ann Rheum Dis 2019;78:896-7

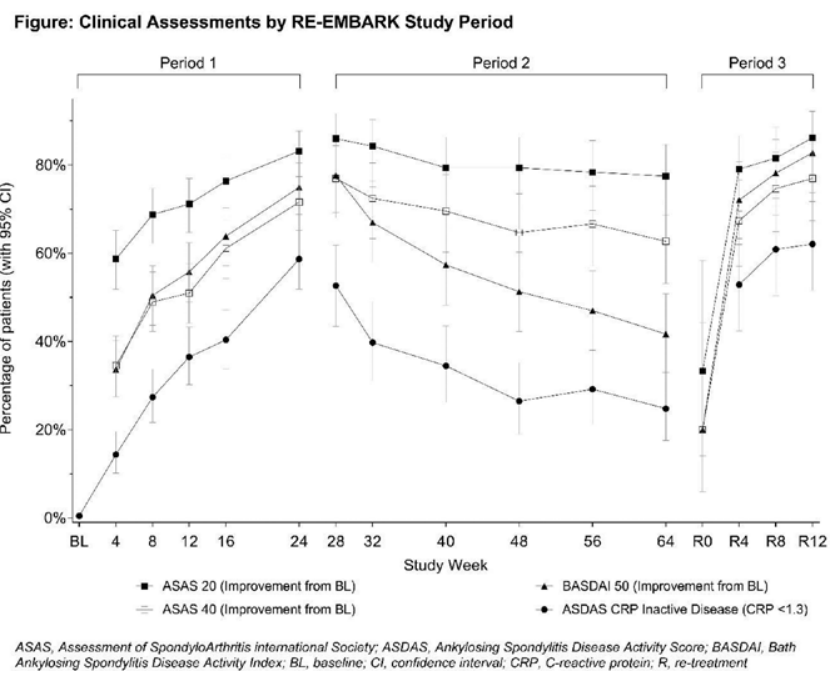

Acknowledgments: Medical writing support was provided by Lorna Forse, $\mathrm{PhD}$, of Engage Scientific Solutions and was funded by Pfizer.

Disclosure of Interests: Filip van den Bosch Consultant of: AbbVie, Celgene Corporation, Eli Lilly, Galapagos, Janssen, Novartis, Pfizer, and UCB, Speakers bureau: AbbVie, Celgene Corporation, Eli Lilly, Galapagos, Janssen, Novartis Pfizer, and UCB, James Cheng-Chung Wei Grant/research support from: AbbVie, Bristol-Myers Squibb, Celgene, Eli Lilly, Janssen, Novartis, Pfizer Inc, UCB Consultant of: AbbVie, Bristol-Myers Squibb, Celgene, Chugai, Eisai, Janssen, Novartis, Pfizer Inc, Sanofi-Aventis, UCB Pharma, Peter Nash Grant/research support from: AbbVie, Bristol-Myers Squibb, Celgene, Eli Lilly and Company Gilead, Janssen, MSD, Novartis, Pfizer Inc, Roche, Sanofi, UCB, Consultant of: AbbVie, Bristol-Myers Squibb, Celgene, Eli Lilly, Gilead, Janssen, MSD, Novartis, Pfizer Inc, Roche, Sanofi, UCB, Speakers bureau: AbbVie, Bristol-Myers Squibb, Celgene, Eli Lilly, Gilead, Janssen, MSD, Novartis, Pfizer Inc, Roche, Sanofi, UCB, Francisco J. Blanco Grant/research support from: Sanofi-Aventis Lilly, Bristol MS, Amgen, Pfizer, Abbvie, TRB Chemedica International, Glaxo SmithKline, Archigen Biotech Limited, Novartis, Nichi-iko pharmaceutical Co Genentech, Jannsen Research \& Development, UCB Biopharma, Centrexion Theurapeutics, Celgene, Roche, Regeneron Pharmaceuticals Inc, Biohope, Corbus Pharmaceutical, Tedec Meiji Pharma, Kiniksa Pharmaceuticals, Ltd Gilead Sciences Inc, Consultant of: Lilly, Bristol MS, Pfizer, Daniela Graham Shareholder of: Pfizer Inc, Employee of: Pfizer Inc, Chuanbo Zang Shareholder of: Pfizer, Employee of: Pfizer, Edmund Arthur Shareholder of: Pfizer, Employee of: Pfizer, Cecilia Borlenghi Shareholder of: Pfizer, Employee of: Pfizer, Bonnie Vlahos Shareholder of: Pfizer, Employee of: Pfizer, Atul Deodhar Grant/ research support from: AbbVie, Eli Lilly, GSK, Novartis, Pfizer, UCB, Consultant of: AbbVie, Amgen, Boehringer Ingelheim, Bristol Myer Squibb (BMS), Eli Lilly, GSK, Janssen, Novartis, Pfizer, UCB, Speakers bureau: AbbVie, Amgen, Boehringer Ingelheim, Bristol Myer Squibb (BMS), Eli Lilly, GSK, Janssen, Novartis, Pfizer, UCB

DOI: 10.1136/annrheumdis-2020-eular.1322

\section{\begin{tabular}{|l|l}
\hline OP0108 RANDOMIZED CONTROLLED TRIAL OF \\
\hline
\end{tabular} ORAL CORTICOSTEROIDS IN AXIAL SPONDYLOARTHROPATHY: MODIFIED COBRA REGIME}

D. Mishra ${ }^{1}$, G. Naidu ${ }^{1}$, V. Kumar ${ }^{1}$, S. K. Sharma ${ }^{1}$, A. Sharma ${ }^{1}$, S. Jain ${ }^{1}$, V. Dhir ${ }^{1}$. ${ }^{1}$ Postgraduate Institute of Medical Education and Research, Chandigarh, India

Background: There is an unmet need of anti-inflammatory agents in AxSpA after NSAID failure. This is especially true for patients with persisting high disease activity and not having access to anti-TNFa. In this regard, corticosteroids may be helpful as a short-term measure. However, current guidelines recommend against oral corticosteroids citing insufficient evidence of efficacy. ${ }^{1}$. Also, there is an assumption that the dose required for benefit is much higher than RA and thus untenable. It is unclear whether starting with a high dose followed by rapid taper would be effective (like the COBRA regime in $R A)^{2}$.

Objectives: To study the efficacy of the COBRA regime of oral corticosteroids in axial SpA over 24 weeks.

Methods: This was a double blind placebo controlled randomized trial. Patients with active axial SpA (BASDAI $\geq 4$ ) despite NSAIDs were randomized to either 
receive oral prednisolone or placebo as per COBRA regime, started on oral prednisolone at a dose of $60 \mathrm{mg}$, rapidly tapered weekly to reach a dose of $10 \mathrm{mg}$ by 6 weeks and subsequently maintained on a low dose of $5 \mathrm{mg}$ till 24 weeks. Primary end point was $50 \%$ improvement in BASDAI at week 24 . Secondary end points were improvement in ASDAS and BASFI. Analysis was by intention-to-treat. Trial Registration\# CTRI/2018/01/011342

Results: This study enrolled 65 patients (62 males) who were randomized to corticosteroid $(n=32)$ or placebo $(n=33)$ with mean \pm SD age $28.5 \pm 8.4$ years and BASDAI $5.4 \pm 1.0$. Primary end point was reached in $12(37.5 \%)$ and $3(9 \%)$ patients treated with steroids and placebo respectively $(p=0.007)$. On repeated measures analysis by general linear model, there was a significant difference between the two-groups in BASDAI $(p=0.03)$ (Figure-1). Patients in the corticosteroid group had significant improvement in BASDAI, ESR, CRP, ASDAS ESR and ASDAS CRP at 24 weeks (Table-1). Clinically important improvement in ASDAS CRP was achieved by significantly higher number of patients in steroid group (17 (55\%) vs 6 $(18 \%), p=0.002)$. Major improvement in ASDAS ESR and ASDAS CRP was also higher in the steroid group (Figure-2). At 24 weeks, patients in the steroid group had significant reduction in IL-6 levels compared to that in placebo group $(p=0.007$, data for 41 patients). Patients in the steroid group had more weight gain and facial puffiness, however no serious adverse events were noted in both the groups.

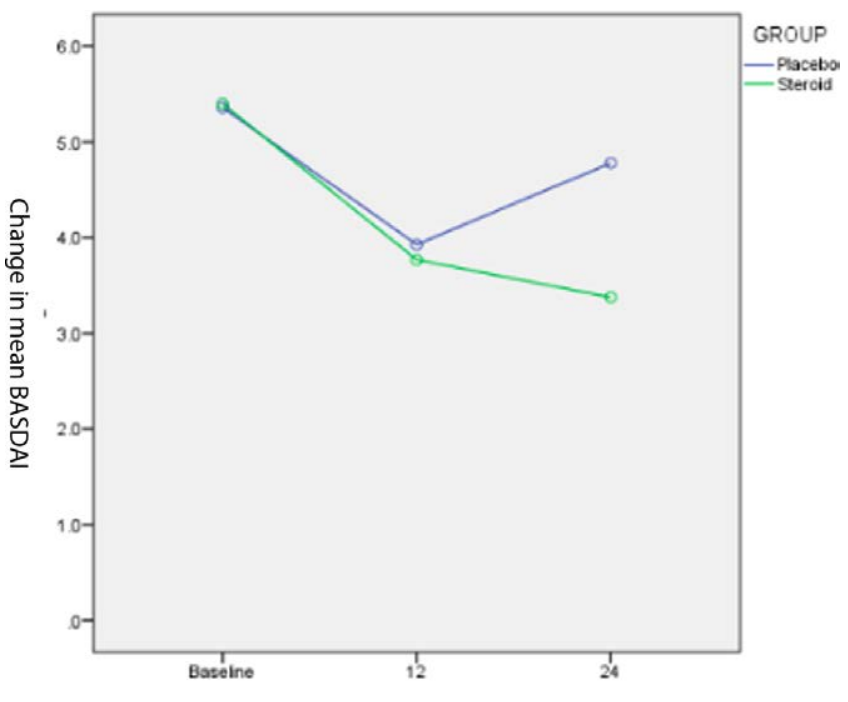

Study period (weeks)

Figure 1. Change in mean BASDAI

Table 1. Changes in disease indices and inflammatory markers at 24 weeks

\begin{tabular}{lccc}
\hline Changes in Parameters (24 weeks-baseline) & Placebo & Corticosteroid & P value \\
\hline ESR, Median (IQR) & $0(-11$ to 21$)$ & $-13(-37$ to 4$)$ & 0.01 \\
CRP mg/L & $0(-8.8$ to 13$)$ & $-9(-22.7$ to 0$)$ & 0.03 \\
Median (IQR) & & & \\
BASDAI (mean \pm SD) & $-0.51 \pm 1.6$ & $-1.88 \pm 2.5$ & 0.03 \\
BASMI (mean \pm SD) & $-0.25 \pm 0.8$ & $-0.56 \pm 0.9$ & 0.23 \\
BASFI (mean \pm SD) & $-0.35 \pm 2.3$ & $-1.48 \pm 3.1$ & 0.28 \\
BAS-G (mean \pm SD) & $-1.02 \pm 2.7$ & $-1.86 \pm 2.5$ & 0.32 \\
ASDAS-ESR (mean \pm SD) & $-0.13 \pm 1.0$ & $-1.11 \pm 1.1$ & 0.001 \\
ASDAS-CRP (mean \pm SD) & $-0.24 \pm 1.1$ & $-1.17 \pm 1.3$ & 0.006 \\
\hline
\end{tabular}

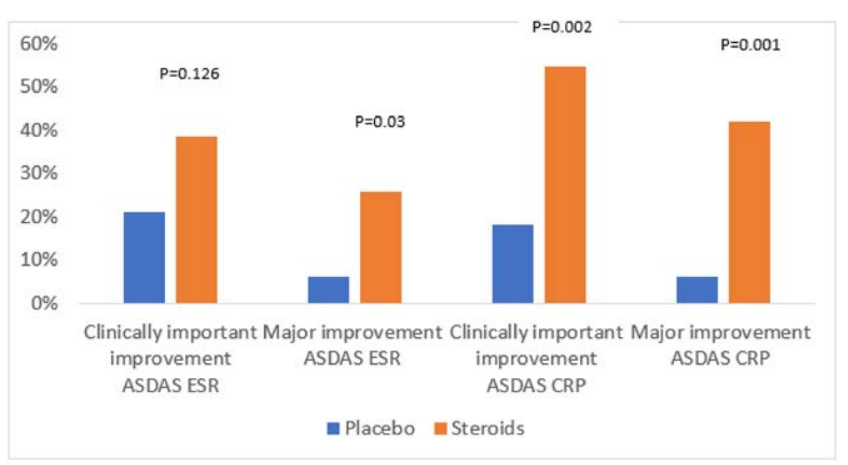

Figure 2. Clinically important and Major improvement at 24 weeks
Conclusion: Oral prednisolone given by COBRA regime was associated with significant improvement in disease activity scores in axial SpA at 24 weeks. This extends and supports results from a previous short term study. ${ }^{3}$ Thus, corticosteroids may be an option for patients not having access to biologics, atleast for the short-term.

\section{References:}

[1] Ward M W, Deodhar A, Gensler L S et al 2019 Update of the American College of Rheumatology/ Spondylitis Association of America/Spondyloarthritis Research and Treatment Network Recommendations for the Treatment of Ankylosing Spondylitis and Nonradiographic Axial Spondyloarthritis. Arthritis \& Rheumatology; 71:1599-1613(2019).

[2] Landewé RB, Boers $M$, Verhoeven AC et al. COBRA combination therapy in patients with early rheumatoid arthritis: long-term structural benefits of a brief intervention. Arthritis Rheum.Feb;46(2):347-56 (2002).

[3] H Haibel, C Fendler,J Listing et al. Efficacy of oral prednisolone in active ankylosing spondylitis: results of a double-blind, randomised, placebo-controlled short-term trial. Ann Rheum Dis;73:243-6 (2014).

Disclosure of Interests: None declared

DOI: 10.1136/annrheumdis-2020-eular.4746

\begin{tabular}{|l|l}
\hline OP0109 & CO-MEDICATION WITH A CONVENTIONAL \\
SYNTHETIC DMARD IN PATIENTS WITH AXIAL \\
SPONDYLOARTHRITIS IS ASSOCIATED WITH \\
IMPROVED RETENTION OF TNF INHIBITORS: \\
RESULTS FROM THE EUROSPA COLLABORATION
\end{tabular}

M. Nissen ${ }^{1}$, B. Delcoigne ${ }^{1}$, D. DI Giuseppe ${ }^{1}$, L. T. H. Jacobsson ${ }^{1}$, K. Fagerli ${ }^{1}$, A. G. Loft ${ }^{1}$, A. Ciurea ${ }^{1}$, D. Nordström ${ }^{1}$, Z. Rotar ${ }^{1}$, F. lannone ${ }^{1}$, M. J. Santos ${ }^{1}$, M. Pombo-Suarez ${ }^{1}$, B. Gudbjornsson ${ }^{1}$, H. Mann ${ }^{1}$, N. Akkoc ${ }^{1}$, C. Codreanu ${ }^{1}$, I. Van der Horst-Bruinsma ${ }^{1}$, B. Michelsen ${ }^{1}$, G. Macfarlane ${ }^{1}$, M. L. Hetland ${ }^{1}$, M. Tomsic ${ }^{1}$, B. Moeller ${ }^{1}$, P. Ávila-Ribeiro ${ }^{1}$, C. SánchezPiedra $^{1}$, H. Relas ${ }^{1}$, A. J. Geirsson ${ }^{1}$, L. Nekvindova ${ }^{1}$, G. Yildirim Cetin ${ }^{1}$ R. Ionescu ${ }^{1}$, N. Steen Krogh ${ }^{1}$, J. Askling ${ }^{1}$, B. Glintborg ${ }^{1}$, U. Lindström ${ }^{1}$ EuroSpA Research Collaboration, on behalf of the DANBIO (Denmark), ARTIS (Sweden), SCQM (Switzerland), NOR-DMARD (Norway), ATTRA (Czech Republic), Reuma.pt (Portugal), BIOBADASER (Spain), ROB-FIN (Finland), biorx.si (Slovenia), ICEBIO (Iceland), TURKBIO (Turkey), RRBR (Romania), ARC (Netherlands), BSRBR-AS (United Kingdom), GISEA (Italy), Copenhagen, Denmark

Background: Axial spondylarthritis (axSpA) patients treated with a tumour necrosis factor inhibitor (TNFi) may receive a concomitant conventional synthetic disease-modifying anti-rheumatic drug (csDMARD), although the value of combination therapy remains unclear.

Objectives: Describe the proportion and phenotype of patients with axSpA initiating their first TNFi as monotherapy compared to TNFi+csDMARD combination therapy, and to compare the 1-year TNFi retention between the two groups.

Methods: Data from 13 European registries was collected. Two exposure treatment groups were defined: TNFi monotherapy at baseline (=TNFi start date) and TNFi+csDMARD combination therapy. TNFi retention rates were assessed with Kaplan-Meier curves for each country and combined. Hazard ratios (HR, 95\% $\mathrm{Cl}$ ) for discontinuing the TNFi were obtained with Cox models: (i) crude; adjusted for (ii) country, and (iii) country, sex, age, calendar year, disease duration and BASDAI. Participating countries were dichotomized into two strata, depending on their 1-year retention rate being above (stratum A) or below (stratum B) the average retention rate across all countries.

Results: 22,196 axSpA patients were included with $34 \%$ on TNFi+csDMARD combination therapy. Baseline characteristics are presented in table 1. Overall, the crude TNFi retention rate was marginally longer in the combination therapy group $(80 \%(79-81 \%))$ compared to the monotherapy group $(78 \%(77-79 \%)$ and was primarily driven by differences in stratum B (fig. 1). TNFi retention rates varied significantly across countries (range:- $11.0 \%$ to $+11.3 \%$ ), with a clear distinction between the 2 strata. The HRs for discontinuation over 1-year (reference=TNFi monotherapy) in the 3 models were: (i) 0.88 (0.82-0.93), (ii) 0.87 (0.82-0.92), (iii) 0.88 (0.82-0.93).

Conclusion: Considerable differences were observed across countries in the use of combination therapy and TNFi retention in axSpA patients. The overall 1-year TNFi retention was higher with csDMARD co-therapy compared to TNFi monotherapy. TNFi monotherapy had a $12-13 \%$ higher risk of treatment discontinuation.

Acknowledgments: Novartis Pharma AG and IQVIA

$\mathrm{MN}$ and BD participated equally

Disclosure of Interests: Michael Nissen Grant/research support from: Abbvie, Consultant of: Novartis, Lilly, Abbvie, Celgene and Pfizer, Speakers bureau: Novartis, Lilly, Abbvie, Celgene and Pfizer, Bénédicte Delcoigne: None declared Daniela Di Giuseppe: None declared, Lennart T.H. Jacobsson Consultant of: AbbVie, Eli Lilly, Janssen, Novartis and Pfizer, Karen Fagerli: None declared, 